\title{
Studying the Mediating Role of Marketing Effectiveness on the Relationship between Organizational Culture and Business Performance (Case study: Hotels of Isfahan City)
}

\author{
Dr. Sayyed Akbar Nilipour Tabatabaei \\ Faculty Member of Shakhes Pajouh Engineering Research Institute \& Assistant Professor, Malek \\ Ashtar University of Technology, Isfahan, Iran \\ Mohammad Hassan Tanhaei \\ Ph.D Student of Human Resources in Engineering Research Institute of Natural Hazards, \\ Shakhespajouh, Isfahan, Iran

\section{Iman Hirmanpour} \\ Department of Management and Accounting, Islamic Azad University, Mobarakeh Branch, \\ Isfahan, Iran \\ DOI: $\quad 10.6007 /$ IJARBSS/v4-i3/679 URL: http://dx.doi.org/10.6007/IJARBSS/v4-i3/679
}

\begin{abstract}
The competitive environment of modern day business appears to enforce organizations to seek new core competencies in order to gain new competitive advantages if they are to survive in the market. The main purpose of this paper is to establish a theoretical and empirical basis that shows the impact of cultural factors on business performance, regarding marketing effectiveness as the mediating variable. Hotels' managers of Isfahan were the population of the study. Random sampling method was used for collecting data. In order to analysis the relationships between organizational culture, marketing effectiveness and business performance structural equation modeling (SME) is used. The findings indicate that customer closeness, organizational values and market orientation as the components of organizational marketing culture can affect marketing effectiveness. These findings also confirm the impact of marketing effectiveness on business performance.
\end{abstract}

Keywords: business performance, marketing effectiveness, market orientation, customer closeness, organizational culture, hotel industry. 


\section{Introduction}

The competitive environment of modern day business appears to enforce organizations to seek new core competencies in order to gain new competitive advantages if they are to survive in the market. Given the fact that customer needs and wants are changing every day, performance measures to determine successful organizations vary to match those switching preferences. Hence, organizations performing in such an unstable, competitive environment have to adapt new performance criteria through anticipating customers' future needs and attempting to meet those needs more quickly and more appropriate than competitors. However, the main question is how organizations could achieve this objective. In other words, what are the antecedents of higher levels of performance? Previous researches have introduced a couple of factors which are to enhance business performance directly and indirectly. The importance of a firm's culture has received considerable interest from both researchers and practitioners in recent years (Webster, 1995). Scholars believe in organizational culture components to influence business performance through affecting employees' marketing attitudes and firm's marketing outcomes that necessitate the successful implementation of marketing, if a firm is to enhance in its performance (Raju et al, 2011; Chi et al, 2007; Webster; 1995; Sin and Tse, 2000). This study aims to examine the impact of organizational culture components namely customer closeness, organizational values and market orientation on marketing effectiveness and the impact of marketing effectiveness on business performance. Since, the existing literature and previous studies are presented in the first part and the conceptual model is proposed based on the hypotheses driven by the literature. Finally, the findings of the study are discussed.

\section{Literature review}

\section{2-1. Organizational Culture and Marketing Effectiveness}

In recent years, the concept of culture, and in particular organization culture, has been put forth in the popular and scholarly literatures (Webster, 1995). Organizational culture refers to shared values, assumptions and norms among organizational members (Schein, 1985). Organizational culture as a set of shared values contributes organization's members to understand organizational functioning and consequently lead their thinking and behavior (Ghorbani et al., 2012). Organizational culture reflects the nebulous, informal, and hidden forces in an organization that influence behavior and productivity of its employees tremendously, even more than written, formal policies and guidelines (Webster, 1995). Zheng et al, (2010) believe that organizational culture is a key factor to organizational effectiveness and it can be seen as a source of sustainable competitive advantage. A number of scholars have studied the relationship between organizational culture and the marketing of services (Parasuraman, 1986). Based on previous studies it can be considered that organizational culture can influence market orientation - an important factor of organizational effectiveness and customer orientation (Ghorbani et al., 2012). There are two major theoretical orientations hypothesizing the influence of organizational culture on marketing effectiveness. The first perspective developed by Anderson (1982) is the constituency-based theory positing that a firm is to satisfy the long-term needs of customers so that it can be effective in a marketing sense. According to this theory firms to implement the marketing concept and achieve marketing 
effectiveness must provide an appropriate marketing culture. The second theory is the market value theory presented by Kotler (1988). This theory also suggests that all major decisions within a firm are made to be returned in the future. Such decisions are treated as investments. Therefore, the decisions to establish a strong marketing culture (i.e. to upgrade service quality, to innovate, etc.) are made to lead to long-term customer satisfaction, which in turn is likely to lead to marketing effectiveness. According to Kotler (1988) investments in first the customer and then in front-line employees are ultimately the key to marketing effectiveness (Webster, 1995). Sin and Tse (2000) also found a positive relationship between culture and marketing effectiveness. Using a marketing perspective, they believe that organizational culture compromises three main components: Customer closeness, organizational values and market orientation. In accordance with previous studies focusing on the linkage between organizational culture and marketing effectiveness, this study investigates the probable influence of cultural dimensions presented by Sin and Tse (2000) on marketing effectiveness. Therefore, the following statements are hypothesized:

H1: Customer closeness can influence marketing effectiveness in a positive way.

H2: Organizational values can influence marketing effectiveness in a positive way.

H3: Market orientation can influence marketing effectiveness in a positive way.

\section{2-2. Marketing effectiveness and Business Performance}

The concept of marketing effectiveness has gained a considerable attention by academics and practitioners over the last few years (Appiah-Adu et al., 2001; Norburn et al., 1990; Lie et al., 1992). It highlights the importance of market knowledge for the firms as it is notable to recognize the importance of studying the market, identify the existing opportunities, select the most appropriate segments of the market to operate in and attempt to offer superior values to meet the customers' needs, wants and preferences. Moreover, the firm must be suitably equipped to be able to perform marketing analysis, planning and implementation. Kotler (1997) has operationalized marketing effectiveness asserting that it compromises five main components: 1) customer philosophy, 2) integrated marketing organization, 3) adequate marketing information, 4) strategic orientation, and 4) operational efficiency (Sin and Tse, 2000). What determine marketing effectiveness are organizational members and individuals that are to be committed to a common set of corporate beliefs and values. These norms develop a suitable environment for management to develop a dynamic organization by displaying a commitment to personal empathy and fostering a customer response of perceived quality (Appiah-Adu et al., 2001). Studies conducted in different countries such as Britain, Australia and Japan to investigate determinants of superior performance of some firms concluded that a common characteristic of the best performing firms was marketing effectiveness (Kiel et al., 1986; NEDO, 1982). On the other hand, Ghosh et al. (1994) found that better performing businesses in Australia, New Zealand and Singapore had provided more commitment to marketing activities than their relatively poor performing competitors. Similar findings were found by Dunn et al. (1994). They concluded that in the USA firms with lower levels of performance placed less importance on performance measures such as profit-to-sales ratio, market share, new product development and market development than their marketing active counterparts. Furthermore, Kotler (1997) argued that marketing effectiveness not only will distinguish the amateur from the professional players in the global market, but also has the 
capability to base a new sphere of economic prosperity and higher living standards. According to mentioned argues, it can be claimed that marketing effectiveness is associated with higher levels of business performance (Appiah-Adu et al., 2001). Webster (1995) also asserted that marketing effectiveness is strongly associated many valuable organizational outcomes like enhanced customer satisfaction, stable and long-term growth, competitive advantage, and a strong marketing orientation. Therefore the relationship between marketing effectiveness and business performance is predicted as:

H4: Marketing effectiveness can influence business performance in a positive way.

The conceptual model of study then is developed based on presented literature and proposed hypotheses (figure 1).

\section{Research Method}

\section{3-1. Sample and Data Collection}

The purpose of this study is to investigate the relationship between organizational culture and marketing effectiveness and also the impact of marketing effectiveness on business performance. Statistical population of the study includes managers of hotels and organizations performing within hotel industry of Isfahan. In order to collect data a sample of 200 respondents was chosen by stratified random sampling, although a total of 150 usable questionnaires out of 200 were returned, which demonstrates a response rate of 75 percent. This study is a descriptive and applied research which has been conducted in a survey method. The data gathering has been done through a self administered questionnaire compromising five elements to study with a total of 37 questions. All items in the questionnaire are measured by Likert's five-point scale. In this study, measures assessing business performance were adopted from Appiah-Adu et al., (2001) in order to extract the status of business performance. Items measuring marketing effectiveness were modified from Webster, (1995), assessing respondents' perception of the marketing effectiveness and its impact on business performance and the items assessing elements of organizational culture were adapted from Zheng et al, (2010) and Sin and Tse, (2000) which capture organizational members' perceptions of the current status of three cultural dimensions (customer closeness, organizational values and market orientation).

\section{Findings}

\section{4-1. Data Analysis}

The reliability of the questionnaire was calculated by means of Cronbach alpha coefficient and estimated to be 0.841 for the items assessing organizational culture, 0.908 for the items of marketing effectiveness and 0.792 for the items of business performance, while the total estimated coefficient equals 0.895 . The content validity of the questionnaire was also confirmed by means of Confirmatory Factor Analysis (CFA). CFA on the items measuring investigated factors confirmed the suitability of the measures to be used for further analysis (Table 1). 


\section{4-2. Hypotheses Testing}

Structural Equation Analyses (SEM) has been used to test the research's hypotheses via LISREL software. SEM technique allows researcher to have a simultaneous estimation of multiple regression equations in a single framework and makes it possible to estimate all the relationships in the model simultaneously, and thus the method allows all the interrelationships among the variables to be assessed in the same decision context. Scholars recommend that an appropriate sample size for Structure Equation Model (SEM) analysis is in the range of 100 to 200 (Bollen, 1989). The sample size in this study was 150, so SEM analysis could be applied. The results demonstrated in table 1 and based on Structural Equation Analyses can confirm the proposed model. Covariance matrices were analyzed in all cases (Table 2). Other results based on LISREL's output are presented in table 3, proving that the proposed model exhibits a reasonably good fit to the data. The principal model of research is illustrated in figure 2. Circumstantial evidence $t$ was also used to find out if proposed relationships are significant or not (figure 3). This evidence reflects the proportion of each parameter's coefficient to the standard deviation error of that parameter which will be significant when it is higher than 2 ( $t$ $\geq 2)$ in t-test and higher than $1.96(z \geq 1.96)$ in $z$-test. Figure 3 demonstrates no insignificant paths. According to table 3 , as expected in the first three hypotheses, organizational culture elements (customer closeness, organizational values and market orientation) were found to influence marketing effectiveness positively $\left(\gamma_{1}=0.35, \gamma_{2}=0.20, \gamma_{3}=0.41, p<0.05\right)$. In a same way, the significant and positive relation between marketing effectiveness and business performance was supported $\left(\gamma_{5}=0.65, p<0.05\right)$. Therefore, marketing effectiveness is associated with business performance.

\section{Discussion}

The main purpose of this study was to investigate how organizational marketing culture can influence the effectiveness of organizations' marketing activities to achieve a better insight about the importance of providing an appropriate cultural context in which marketing schemes could be planned and implemented effectively and the benefits derived by using this approach for both organization and customers and also what an important role can marketing effectiveness can play to enable the organization achieve to higher levels of performance. The findings indicate that organizational culture can influence marketing effectiveness, and marketing effectiveness, in turn can affect business performance. Based on these findings, the more importance organization places on the provision of marketing culture including customer closeness, organizational values, and market orientation the more effective would be marketing activities and consequently the higher levels of performance will be recorded for the organization. As noted in the literature context in some cases the influence of organizational culture on employees is more significant than formal structures that reflects the importance of its role in organization goal achieving and in particular in the sphere of marketing endeavors. On the other hand, market information and other outcomes derived by marketing effectiveness is proved to lead to higher levels of core competencies such as customer satisfaction, customer retention and customer loyalty which can redound to other tangible and intangible organizational outcomes. Marketing can be regarded as the pivotal force behind strategic planning and business operations, and hence, as an intrinsic component of organizational 
efforts. It asserts the significance of marketing effectiveness as a key determinant of business performance. These findings have considerable applications for both management and employees in the field of effective antecedents of business performance through highlighting the crucial role of marketing culture and effectiveness in business success.

\section{References}

Anderson, P.F. (1982). Marketing, strategic planning, and the theory of the firm, Journal of Marketing, 46, 15-26.

Appiah-Adu, k, Fyall, and Singh, S. (2001). Marketing effectiveness and business performance in the financial services industry. Journal of Services Marketing, 15 (1), 18-34.

Bollen, Kenneth A.(1989). Social sciences; Latent variables; Statistical methods. Newyork; willey.p,514 .

Chi, h. K, Yeh, H. R and Chen, Y. L. (2007).The Mediating Effect of Knowledge Management on Customer Orientation and Job Performance of Salespeople.

Dunn, M., Norburn, D. and Burley, S. (1994). The impact of organisational values, goals and climate on marketing effectiveness, Journal of Business Research, 30,131-41.

Ghorbani, H, Abdollahi, M and Khorsandnejad, A. (2012). An empirical investigation of the relationship between organizational culture and customer orientation: the mediating effect of knowledge management (an empirical study in the household appliance industry in Iran), International Journal of Marketing Studies, 4(3), 58-67.

Ghosh, B., Schoch, H., Huang, J., Lai, W. and Hooley, G. (1994). A comparative study of marketing effectiveness: profiles of top performers in Taiwan and Singapore, Journal of International Marketing and Marketing Research, 19 (2), 75-97.

Kiel, G., McVey, V. and McColl-Kennedy, J.R. (1986). Marketing planning practices in Australia, Management Review, 1, 21-9.

Kotler, P. (1988). Marketing Management, Prentice-Hall, Englewood Cliffs, NJ.

Kotler, P. (1977). From sales obsession to marketing effectiveness, Harvard Business Review, November-December,67-75.

Lai, W.B., Huang, J.Y., Hooley, G., Lynch, J. and Yau, O. (1992). Effective marketing in Taiwan: profiles of the top performers, European Journal of Marketing, 26 (3), 5-17.

NEDO (1982), Innovation in the UK. 
Norburn, D., Birley, S., Dunn, M. and Payne, A. (1990). A four-nation study of the relationship between marketing effectiveness, corporate culture, corporate values, and market orientation, Journal of International Business Studies, third quarter, 451-68.

Parasuraman, A., Zeithaml, V. and Berry, L.L. (1986). SERVQUAL: a multiple-item scale for measuring customer perceptions of service quality, working paper, Marketing Science Institute, Cambridge, MA.

Raju, P.S, Lonial, S. C and Crum, M. D. (2011).Market orientation in the context of SMEs: A conceptual framework, Journal of Business Research, 64, 1320-1326.

Schein, E. H. (1985). Organizational culture and leadership: a dynamic view. San Francisco, CA: Jossey-Bass.

Sin, L and Tse, A. (2000). How does marketing effectiveness mediate the effect of organizational culture on business performance? The case of service firms. Journal of Services Marketing, 14, (4), 295-309.

Webster, C. (1995). Marketing culture and marketing effectiveness in service firms. Journal of Services Marketing, 9(2), 6-21.

Zheng, W, Yang, B, McLean, G. N. (2010). Linking organizational culture, structure, strategy, and organizational effectiveness: Mediating role of knowledge management.Journal of Business Research, 63, 763-771.

\begin{tabular}{|l|l|}
\hline \multicolumn{2}{|l|}{$\begin{array}{l}\text { Table 1. Results of the Confirmatory } \\
\text { Factor Analysis }\end{array}$} \\
\hline chi-square & 231.52 \\
\hline Df & 114 \\
\hline p-value & 0.11 \\
\hline RMSEA & 0.095 \\
\hline
\end{tabular}

Table 2. Fit indices for the path model 


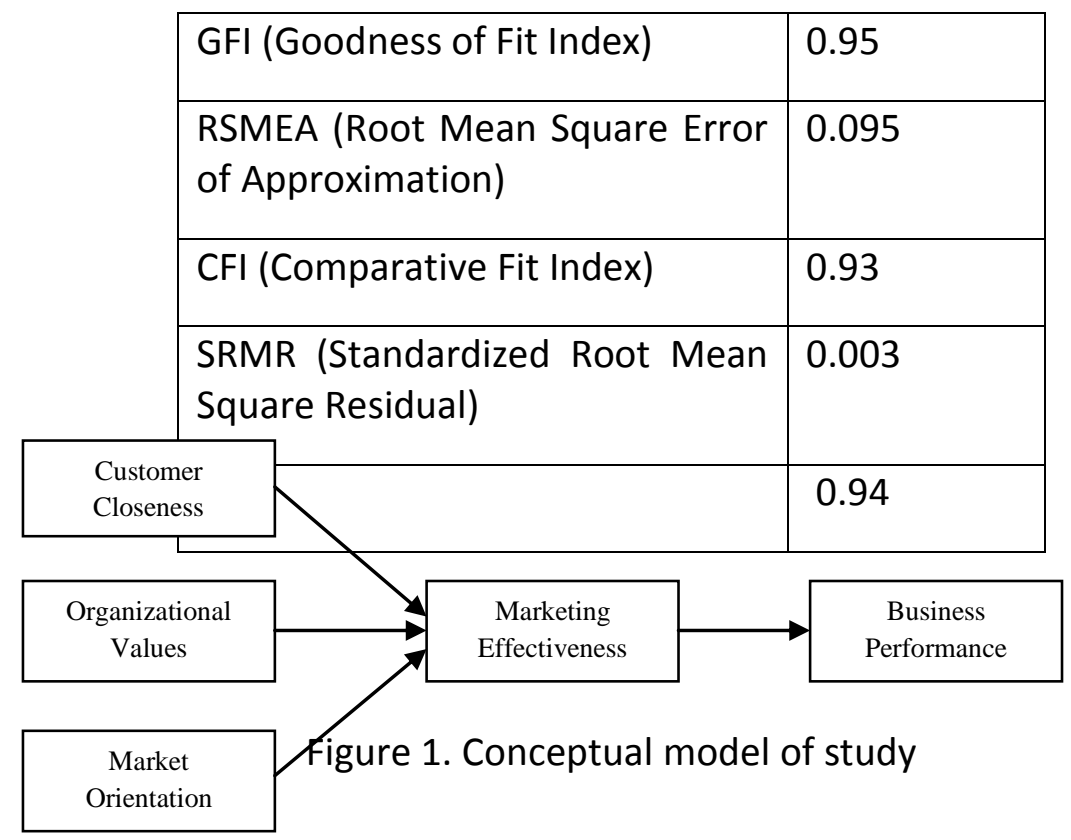

\begin{tabular}{|c|c|c|c|c|c|}
\hline Independent variable & Dependent variable & Hypotheses & Coefficient & $\begin{array}{l}\text { T- } \\
\text { value }\end{array}$ & $p$ \\
\hline Customer closeness & $\begin{array}{l}\text { Marketing } \\
\text { effectiveness }\end{array}$ & $\mathrm{H} 1$ & 0.75 & 5.45 & $<0.05$ \\
\hline Organizational values & $\begin{array}{l}\text { Marketing } \\
\text { effectiveness }\end{array}$ & $\mathrm{H} 2$ & 0.52 & 8.96 & $<0.05$ \\
\hline Market orientation & $\begin{array}{l}\text { Marketing } \\
\text { effectiveness }\end{array}$ & $\mathrm{H} 3$ & 0.63 & 11.48 & $<0.05$ \\
\hline Marketing effectiveness & $\begin{array}{l}\text { Business } \\
\text { performance }\end{array}$ & $\mathrm{H} 4$ & 0.41 & 16.01 & $<0.05$ \\
\hline
\end{tabular}




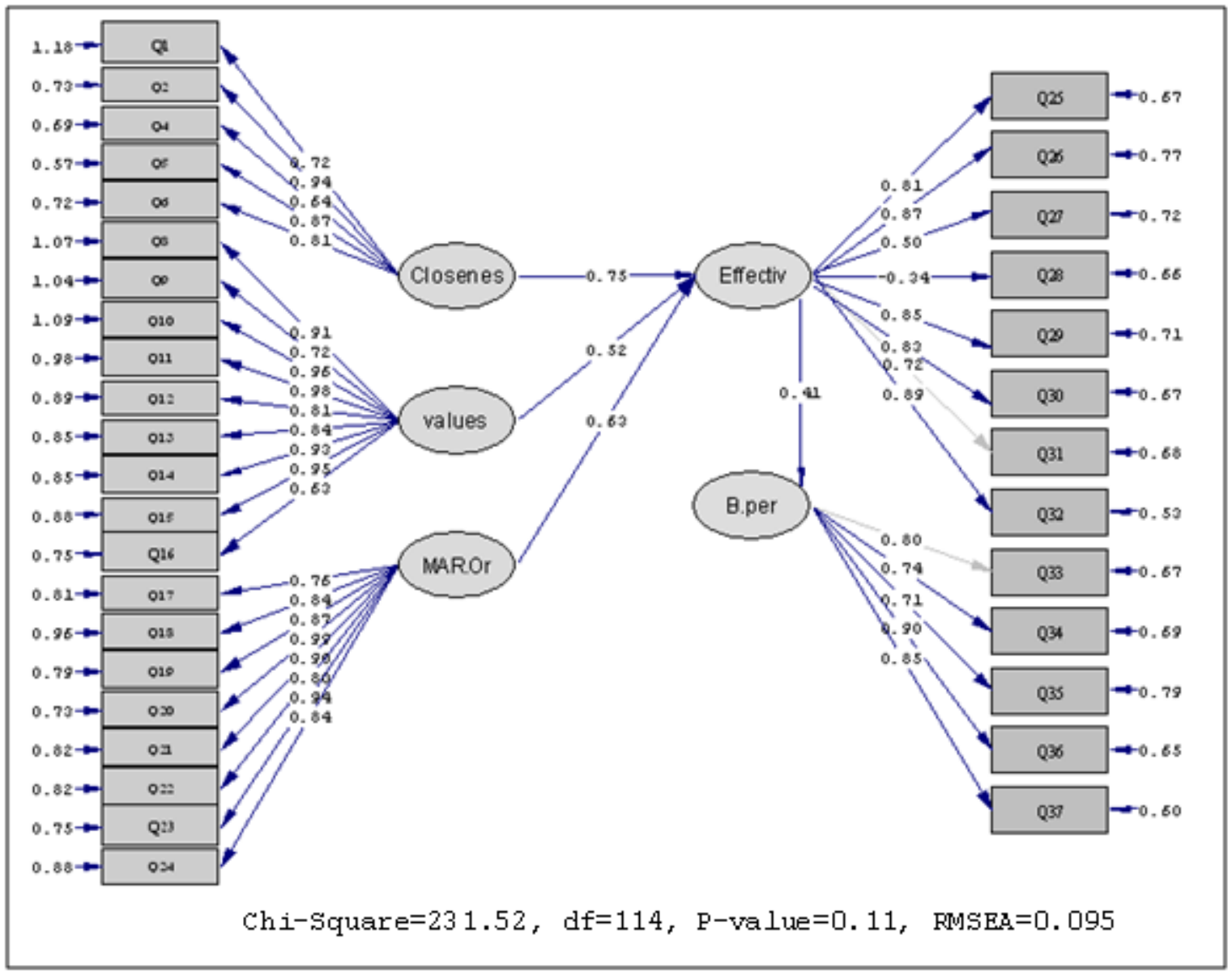

Figure2 . Principal Model of Research 